\title{
Gestión de liderazgo y los valores en la educación
}

\author{
Leadership management and values in education. \\ Gestão de Liderança e os valores da Educação
}

DOI: https://doi.org/10.21803/pensam.v12i22.250

\section{Ana Zulema Castro Salazar \\ Fanny Cadme Galabay \\ https://orcid.org/0000-0001-5815-6671 \\ Ana Lucia Naspud Bonete}

\section{¿Cómo citar este artículo?}

Castro, A., Cadme, F. \& Naspud, A. (2019). Gestión de liderazgo y los valores en la educación. Pensamiento Americano, 12(23) 105-126.

DOI: https://doi.org/10.21803/pensam.v12i22.250

\section{Resumen}

El desarrollo de la presente investigación se realizó en La unidad Educativa Luis Rogelio González de la ciudad de Azogues, provincia del cañar, país Educador, con jornadas matutina y nocturna. Se utilizó el proceso descriptivo, analítico- sintético y la triangulación de la información teórica con los datos de la realidad y el criterio de los investigadores, utilizando las herramientas de encuestas, cuestionarios y entrevistas; con la aplicación de dichas herramientas a directivos, docentes, padres de familia y estudiantes, con los resultados se pudo determinar claramente que en la institución educativa no cuenta con plan estratégico, el cual es uno de los principales procesos para la gestión interna, así como no se ejecutan proyectos de capacitación continua dirigidos a los directivos y docentes; y, la escasa o nula importancia sobre los valores en los estudiantes de esta institución.

Palabras Clave: Gestión, liderazgo, valores, educación, docentes, estudiantes, autoridades.

\begin{abstract}
This research was carried out in the Luis Rogelio González Educational Unit of the city of Azogues, province of Cañar, country Educator, with morning and night conferences. The descriptive, analytical-synthetic process and the triangulation of the theoretical information with the real data and the criteria of the researchers were used, using the tools of surveys, questionnaires and interviews; with the application of these tools to managers, teachers, parents and students, with the results it was clearly determined that the educational institution does not have a strategic plan, which is one of the main processes for internal management, as well as there, are no ongoing training projects aimed at managers and teachers; and, the little or no importance on the values in the students of this institution.
\end{abstract}

Key words: Management, leadership, values, education, teachers, students, authorities. 


\section{Resumo}

O desenvolvimento da presente pesquisa foi feita na Unidade Educativa Luis Rogelio González da cidade de Azogues, província de Cañar, país equatoriano, com jornadas matutina e noturna. Se utilizou o processo descritivo, analítico-sintético e a triangulação da informação teórica com os dados da realidade e o critério dos pesquisadores, utilizando as ferramentas de entrevistas e questionários. Com a aplicação de tais ferramentas a diretivos, docentes, pais e mães de família e estudantes, e seus resultados, foi possível determinar claramente que a instituição educativa não conta com plano estratégico, o qual é um dos principais processos para a gestão interna, assim como não se executam projetos de capacitação contínua dirigidos aos diretivos e docentes; e a escassa ou nula importância sobre os valores nos estudantes desta instituição.

Palavras-chave: Gestão, Liderança, valores, educação, docentes, estudantes, autoridades.

\section{Perfil}

Docente de la Universidad Católica de Cuenca, azcastros@ucacue.edu.ec

Ana Zulema Castro Salazar

Magister en Gerencia y Liderazgo

\section{Perfil}

Docente de la Universidad Católica de Cuenca. fcadmeg@ucacue.edu.co

\section{Fanny Cadme Galabay}

Magister en Gerencia y Liderazgo

\section{Perfil}

Docente de la Universidad Católica de Cuenca. anaspudb@ucacue.edu.ec

Ana Lucia Naspud Bonete

Magister en Gerencia y Liderazgo 


\section{Introducción}

La investigación sobre: Gestión, Liderazgo y valores en la educación es importante en los momentos actuales, en razón que al analizar las estadísticas sobre esta temática a nivel global en el ámbito mundial se identifican que las necesidades o requerimientos para empleo en los países desarrollados consta la educación en segundo lugar, correspondiendo el primero al ámbito de la tecnología.

Entonces la identificación del tema a investigarse se vuelve prioritaria, que servirá de fundamento experiencial para plantear, proyectos de capacitación de mejoramiento. En esta investigación se analizó la capacidad de gestión y valores tanto a los valores personales e institucionales; en donde se determinó que las principales falencias son: No existe gestión de liderazgo, tampoco formación en valores dentro del centro educativo. Ante esta situación se plantea las siguientes posibles soluciones:

- Investigar los referentes teóricos sobre: gestión educativa, y de calidad en valores. Contando con recursos humanos idóneos, mediante programas de formación que faciliten el desarrollo del personal docente, favorezcan su ascenso y el relevo generacional.

- Asumir con responsabilidad la elaboración del diagnóstico institucional en los diferentes escenarios de gestión, liderazgo y valores. Fortaleciendo el liderazgo en la toma de decisiones en situaciones arriesgadas o inciertas.

- Implementar "Planes de Acción" con la utilización de educación en valores dentro del aula. Identificando técnicas que los gerentes y directivos pueden utilizar para reducir las dificultades. Generando propuestas de desarrollo y capacitación que permitan fortalecer las prácticas de liderazgo.

Se invita a Concienciar a los docentes y comunidad educativa en general sobre la importancia de determinar los valores y liderazgo de autoridades, directivos, jefes departamentales y coordinadores de comisiones en la elaboración y ejecución de los planes estratégicos y operativos.

\section{LA GESTIÓN EDUCATIVA}

La gestión educativa busca aplicar los principios generales de la gestión, que han estado presentes en la teoría de la administración, al campo específico de la educación. El objeto de la gestión educativa como disciplina, es el estudio de la organización del trabajo en el campo de la educación, por tanto, está influenciada por teorías de la administración, pero, además, existen otras disciplinas que han permitido enriquecer el análisis, como son: la administración, la filosofía, las ciencias sociales, la psicología, la sociología y la antropología.

Ahora bien, si aceptamos que la filosofía de la educación postula la acción educativa, como una relación dialéctica en la cual, interviene un grupo de sujetos, directivos, profesores, estudiantes y familias de los estudiantes, que toman decisiones y ejecutan acciones, también es necesario reconocer las semejanzas y las diferencias por parte de este grupo de actores, así como, la definición de una serie de acciones concretas que conduzcan a los actores al logro de un objetivo en común. Pero, además, debe entenderse que la educación está relacionada con el encargo social en donde, uno de los fines de la gestión educativa deberá encaminarse a transformar a los individuos y la sociedad.

La gestión "se asimila al manejo cotidiano de recursos materiales, humanos y financieros 
en el marco de una estructura que distribuye atribuciones y responsabilidades y que define el esquema de la división del trabajo" (Martínez, 2000, p.11).

Como manifiesta Del Río Vásquez (2005) manifiesta:

El término gestión tiene relación estrecha con el término inglés Management, el cual fue traducido inicialmente al español como administración y ahora es entendido como gestión de organizaciones, referida al conjunto de conocimientos modernos y sistematizados en relación con los procesos de diagnóstico, diseño, planeación, ejecución y control de las acciones teológicas de las organizaciones en interacción con un contexto social orientado por la racionalidad social y técnica (p.14).

En lo referente al tema de gestión en este caso un centro educativo, dentro del cual deben intervenir los directivos, profesores, estudiantes y representantes que toman decisiones y ejecutan acciones, pero siempre deben estar dirigidos orientados por un líder o gerente. En las instituciones educativas la gestión está precedida por un rector, director, decano que primeramente debe tener un grado emocional, por lo que exige mucha responsabilidad una reestructuración permanente de la institución, debe establecer los equilibrios correspondientes, organizará su tiempo, dosificando la direccionalidad de su hacer cotidiano, dando importancia o prioridad a unas tareas sobre otras. El director debe querer hacer y saber hacer, porque si no está preparado profesionalmente como llevar en adelante la institución, no podría dirigir de la mejor manera para llegar a la eficiencia educativa.

\section{LIDERAZGO EDUCACIONAL}

El alemán Konrad Fiedler, autor de la Teoría de la Consistencia, pone el énfasis en la habilidad para inspirar a los demás, definiendo el liderazgo como "la capacidad de persuadir a otro para que busque entusiastamente objetivos definidos. Es el factor humano que mantiene unido a un grupo y los motiva hacia sus objetivos".

Siguiendo en esta línea, José Alberto Santos concibe el liderazgo como "el proceso de influir sobre sí mismo, el grupo o la organización a través de los procesos de comunicación, toma de decisiones y despliegue del potencial para obtener un resultado útil".

Keith Davis (2003), por su parte, define el liderazgo como "la habilidad de convencer a otros para que busquen con entusiasmo el logro de objetivos definidos" (Aula formativa-online).

\section{Diferencias entre directivo y líder}

La diferencia entre los directivos y los líderes, escribió (Zaleznik), radica en las concepciones que tienen del caosy del orden más profundo de su psiquis. Los directivos abrazan el proceso, buscar la estabilidad y el control, e intentan instintivamente solucionar los problemas con rapidez, a veces incluso antes de que hayan comprendido totalmente la importancia de tales problemas. En cambio, los líderes soportan el caos y la falta de estructura, y están dispuestos a posponer una conclusión con el fin de comprender en mayor profundidad los problemas. En este sentido, afirmaba (Zaleznik), los líderes empresariales tienen mucho más en común con los artistas, los científicos y otros pensadores creativos que con los directivos. Para tener éxito, las organizaciones necesitan tanto a los líderes como a los directivos. El des arrollo de ambos creatividad y la imaginación pueden prosperar.

\section{Personalidad del directivo frente a la del líder}


Una cultura directiva enfatiza la racionalidad y el control. Tanto sus energías se dirigen hacia los objetivos como si se dirigen hacia los recursos, las estructuras de la organización o las personas, la función del directivo es solucionar los problemas. El directivo pregunta: ¿qué problemas hay que resolver y cuál es el mejor modo de obtener resultados de forma que las personas sigan contribuyendo a esta organización? Desde esta perspectiva, el liderazgo es tan solo un esfuerzo práctico para dirigir los negocios. Para llevar a cabo esta tarea con éxito, un directivo exige que muchas personas trabajen de forma eficiente en diferentes niveles de status y responsabilidad. No se precisa ser un genio ni un héroe para ser un directivo, sino más bien perseverancia, tenacidad, trabajo duro, inteligencia capacidad analítico y, quizá los más importante de todo, tolerancia y buena voluntad.

Sin embargo, otra concepción de liderazgo atribuye casi creencias místicas a lo que es un líder. Durante años, las personas han debatido sobre sí el líder nace o se hace. La respuesta es que hay las dos cosas. Hay muchos estilos personales de líderes, algunos son introvertidos y analíticos, otros proclaman sus ideas las cimas de las montañas. La misma importancia tiene el hecho de que diferentes situaciones requieren diferentes tipos de liderazgo. En cualquier caso, casi todos los líderes eficaces se parecen en un rasgo esencial: todos muestran un elevado grado de lo que ha denominado.

\section{Los valores y la Educación}

Hoy en día el tema de los valores tiene una enorme vigencia, se habla de la necesidad de que existen valores en la familia, en la escuela, en la sociedad. Las iniciativas sobre valores están presentes en los colegios, las empresas, algunos medios de comunicación, etc. Y aunque al mismo tiempo se reconozca constantemente la manifestación de conductas carentes de valores en todos los ámbitos y la sociedad sufra las consecuencias de la falta de valores en muchas circunstancias, a nivel mundial parece haber ansia de volver a los valores.

En todas las épocas se ha hablado de un modo u otro de los valores, sin embargo, difícilmente logramos ponernos de acuerdo sobre qué son y cuáles son éstos, pues lo cierto es que a largo de la historia todos los pueblos han considerado valiosos sus descubrimientos, sus costumbres, su arte, su religión, su forma de vida.

¿En qué se nota que una persona, una familia o un pueblo tienen valores? Los valores se notan, entre otras cosas, cuando:

- Se hacen rendir los recursos materiales y se es productivo

- Existen lazos y manifestaciones afectivas positivas entre los sujetos

- Se gusta del orden, la limpieza y la armonía en el lugar donde vive

- Se busca la paz y el progreso del grupo

- Se reconoce la existencia de un ser supremo

- Se aprecia y se cuida la salud del cuerpo

- Se da espacio al estudio y al descubrimiento científico

- Se identifican las conductas del bien y se diferencian del mal

- Se favorece la contemplación y expresión artística.

Todo esto tiene algo en común: es para bien de la persona de la familia y del grupo social. Por tanto, el valor se identifica con el bien en algún sentido. Así pues, es valioso lo que es bueno, lo que es para bien de algo o de alguien.

El valor es tanto un bien que responde a necesidades humanas como un criterio que permite evaluar la bondad de nuestras acciones. Cuando hablamos de valor, generalmente nos 
referimos a las cosas materiales, espiritual, institucionales, profesiones, derechos civiles, etc., que permiten al hombre a realizarse de alguna manera, el valor es entonces captado como un bien ya que identifica con lo bueno, con lo perfecto, con o valioso. El mal es entonces, la carencia o ausencia de bien.

Centremos en el valor moral que perfecciona al hombre en cuanto a ser hombre, en su voluntad, en su libertad, en su razón, lleva a construirse como hombre, a hacerte más humano.

Para los docentes, padres de familia, los valores son un tema insoslayable; pugnar por "la educación en valores" no es una moda, sino la esencia misma de la acción educativa. La educación, o es "en valores" o no es tal, pues los valores son el contenido de la educación, Para educar en los valores hace falta conocerlos bien y habilitare en la metodología apropiada para ello; es decir partir del conocimiento firme de aspectos axiológicos básicos. La axiología y la pedagogía aportan cada una lo que corresponde especialmente a su campo de acción, para hacer posible la educación en valores.

La educación en valores es tarea de toda la vida. Nunca estamos suficientemente educa- dos en algún valor, pues siempre podemos y aspiramos llegar a más. Por tanto, la educación en los valores es nuestra tarea y nuestro compromiso por toda la vida. En cuantos educadores debemos entender que la educación se opera en diferentes hábitos, cada uno de los cuales tiene su responsabilidad específica en la integración de todos los valores para buscar el perfeccionamiento humano.

Aun cuando la familia y la escuela buscan como finalidad última de su acción educativa la formación integral de los chicos corresponde a cada una de manera especial la responsabilidad específica sobre ciertas esferas de valor, en función de su razón de ser como instituciones en la sociedad.

La familia, por ejemplo da la vida a los hijos y, a partir de ello, los acoge y acompaña en la intimidad, razón por la cual es el ámbito propio para educar en los valores "de Intimidad", esto es en aquellos valores relativos a la formación más propiamente humana: los que corresponden al campo de la formación efectiva, al campo de la asimilación de principios de comportamiento acordes con la naturaleza humana, propicios para su propio desarrollo y para no entorpecer el de los demás (formación moral); y al campo de la orientación de la propia vida

Tabla 1.

Finalidad y bipolaridad axiológica

\begin{tabular}{llll}
\hline Esferas de valor & Fin objetivo & Fin Subjetivo & Carencia de Valor \\
\hline Religiosos & Dios & Santidad & La nada \\
Morales & Bondad & Felicidad & Maldad \\
Estéticos & Belleza & Gozo & Fealdad \\
& & & \\
Intelectuales & Verdad & Sabiduría & Falsedad \\
Afectivos & Amor & Agrado, Afecto & Odio \\
Sociales & Poder & Fama, Prestigio & Aislamiento \\
Físicos & Salud & Bienestar físico & Enfermedad \\
Económicos & Bienes & Comodidad & Pobreza \\
& Materiales & & \\
\hline
\end{tabular}

Fuente: Elaboración propia. 
en función de una personal que cada familia y cada sujeto debe dar ante la existencia de Dios (formación religiosa).

Por su parte, al igual que la familia, la escuela posee responsabilidad prioritaria ante la educación en determinadas áreas de valor. La escuela es una institución de origen cultural, creada por la sociedad para apoyar y complementar la acción educativa familiar en aquellos aspectos que rebasen las posibilidades del microambiente familiar: La formación intelectual profunda a través del acercamiento a la ciencia; la formación sociopolítica y cívica al servir a los alumnos de puente entre la familia y la comunidad social.

A la familia y la escuela se unen otros ámbitos e instituciones educativas: Los clubes sociales y deportivos, los templos y parroquias, el vecindario, los ambientes virtuales que cada vez cobran mayor fuerza. Se trata de conseguir, a través de la integración de todas las influencias educativas, el perfeccionamiento integral del ser humano.

Los modos o formas de abordar la acción educativa pueden ser muy variados, pero en todos los casos habrán de considerar básicamente los siguientes tres principios:

1. El ejemplo de los educadores como punto de partida, con el fin de ser reflejo vivo de los valores en los que se desea formar.

2. La convicción vs. La imposición, como propósito que se desea lograr, pues los valores pueden proponerse, pero nunca imponerse.

3. La formación de la voluntad como medio sustancial, pues el perfeccionamiento humano es decisión y tarea personal.

Lo fundamental para la educación en valores será entender cada vez más de fondo qué son los valores cuales son las esferas axiológicas en las que se manifiestan para el desarrollo humano, apuntar al perfeccionamiento integral del hombre como finalidad última, y perseverar en el ejemplo vivo como marco de referencia motivador y en la formación de la inteligencia y de la voluntad, como instrumentos clave en la permanente conquista de la cima de cada una de las esferas de valor.

Metodologías para aplicar en clase:

a. Estrategias de sensibilidad y empatía. - esto significa reflexionar en una escala de valores actuales y en un concepto asociado a las virtudes. El entender valores abstractos requiere de una capacidad de pensamiento que no está presente en los niños pequeños, esto debe tener presente para planificar las actividades.

b. Sensibilización de lo que es la presión de los pares. - Estas pueden ser presiones explicitas e implícitas. Las actividades que se van a llevar a cabo son que los profesores dan una introducción al significado de presión de pares, es decir dándose la debida orientación en las situaciones más frecuentes que los niños enfrentan en su vida diaria. Se debe incentivar a los alumnos mediante cuestionarios que adopten criterios ante situaciones negativas para que de esta manera se trate de combatir el origen de los problemas.

\section{c. Sensibilización de lo que es la presión de los medios de comunicación. - se trata de enseñar a los niños a identificar la manipulación que ejercen los medios de comunicación sobre los valores de las personas, con estas bases se permitirá que el niño más adelante pueda defen- derse de la presión negativas.}


d) comparaciones: Luego de que los niños expresen su opinión sobre temas conflictivos se les pide que comparen sus respuestas con otros alumnos, la idea de esta actividad es que los alumnos logren estar conscientes de los sentimientos o ideas de otros promoviendo la empatía en ellos.

\section{LOS VALORES EN EL CURRÍCULO}

La escuela es un agente socializador y reproductor de valores presentes en la sociedad y que debe destinar un espacio para la educación en valores. Los valores deben estar definidos en el PEI (Plan Educativo Institucional), con los cuales la institución se identifica y plantea desarrollarlos. Más concretamente los valores se hacen presentes en el aula mediante los temas transversales, estos temas transversales van a responder a realidades o necesidades que tiene una muy especial relevancia para la vida de las personas y la construcción de la sociedad, como se ha dicho los temas transversales es una propuesta curricular concreta. En el diseño curricular, la educación en valores se encuentra en los objetivos de enseñanza generales, esta educación es abierta y flexible, es abierta porque cada profesor es su centro, la define y una vez tomada la decisión debe ir en él y en el PCCE (Proyecto Curricular del Centro Educativo).

Los temas transversales forman parte del currículo y están íntimamente relacionados con el sistema de valores. Constituyen ejes de valores de contenido, están presentes en las áreas integradas dentro de ellas. Mencionaré algunos de los valores más frecuentes dentro de la educación:

Honestidad - En el desenvolvimiento de nuestra vida diaria, tanto en el hogar como en el colegio, los adolescentes tienen que tener la suficiente valentía de aceptar tanto sus defectos como sus virtudes, sus equivocaciones y aciertos, lo cual se requiere aprender hacer honestos, moderados, decoros, decentes en cualquier circunstancia de la vida.

Orden. - se está dando inicio a un año escolary los jóvenes bien con el deseo de trabajar muy bien, una manera de lograr las metas personales es organizar el tiempo desde el primer día de clase es para poner en práctica la virtud de orden.

Obediencia. - Vivimos en una época donde se rechaza cualquier forma de autoridad, así como las reglas o normas que todos debemos cumplir. La soberbia y el egoísmo nos hacen sentir autosuficiente, superiores sin rendir nuestro juicio y voluntad ante otros pretextando la defensa de nuestra libertad. Parece claro que el problema no radica en las personas que ejercen una autoridad, tampoco en las normas creadas para mantener el orden, la seguridad y la armonía entre las personas, está dentro de nosotros mismos. Debemos evitar caer en el error de sentir que obedeciendo nos convertimos en seres inferiores y sumisos caracterizados por una libertad mutilada. Por el contrario, la obediencia nos lleva a practicar una libertad más plena, porque echamos por la borda el impedimento para obedecer cabalmente.

Sinceridad. - Se ha optado por la realización de un talle acerca de la sinceridad, porque consideramos que es un valor fundamental para que el alumno se encuentre mentalmente tranquilo y estable, sin ningún remordimiento de haber fingido o mentido en algo y que su conciencia esté tranquila. Otra de las razones es que mediante este valor el alumno logra establecer relaciones interpersonales más fuertes, puesto que si un joven se sincera con otro van a lograr mayor confianza entre los dos y su amistad se hará más fuerte.

La educación en valores, dentro del currículo, como un eje transversal o como un contenido 
de enseñanza aprendizaje que debe impregnar la totalidad de la tarea educativa. Entre las dimensiones de este eje se encuentran el respeto por la vida, la libertad, la solidaridad, la convivencia, la honestidad, la identidad nacional y la perseverancia.

Los valores principalmente deben de ser enseñados en los hogares de cada persona, en el caso educativo de nuestros dicentes, que en la actualidad se está perdiendo esos valores muy importantes que deben ser puestos en práctica en todo momento de las personas, los valores deben ser enseñados y ejemplificados por los padres y miembros de los hogares para que sus discípulos pongan también en práctica; Si en los hogares se practicarán buenos valores, en los establecimientos educativos se continuará inculcándoles y dando ejemplo; pero lamentablemente esto no se da en su totalidad ya que el padre de familia o representante, los docentes y directivos lo han dejado en un segundo plano este tema de suma importancia para la formación integral del ser humano en nuestro caso del estudiantado.

\subsection{Participantes.}

La presente investigación se realizó en la Unidad Educativa "Luis Rogerio González" ubicado en el Ecuador, en la provincia del Cañar, ciudad de Azogues; tipo de establecimiento fiscal; con jornadas Matutina y Nocturna, cuenta con 105 profesores, quienes 51 son maestros de educación básica y 54 de bachillerato, y con un total de alumnado de 1.515 estudiantes. De acuerdo a la muestra seleccionada, se consideró el cálculo de la muestra probabilística aleatoria es de 25 alumnos.

\subsection{Materiales e instrumentos}

Para la investigación se utilizó las siguientes herramientas:
Encuesta a los directivos sobre la información general del establecimiento, tipo de establecimiento, ¿cómo están organizados? ¿Cuáles son las tareas de dicha institución?, el clima de respeto y consenso en la toma de decisiones, resolución de conflictos y promover soluciones pertinentes y oportunas en la toma de decisiones, cómo promueve la administración y liderazgo del centro educativo, las habilidades del liderazgo para dirigir una institución, que promueve para mejorar el desempeño y progreso de la institución escolar como directivo.

Cuestionario de entrevista al rector, vicerrector, supervisor con el objeto de potenciar la propuesta de innovación para la gestión de la organización sustentada en valores y liderazgo. Encuesta a los docentes sobre datos de identificación, tipo del establecimiento. -el cuestionario a los docentes sobre declaraciones del rol del docente líder se define como una persona que posee la actitud y las habilidades para cuestionar las órdenes existentes. El Liderazgo en la unidad educativa está intrincadamente ligado a la búsqueda de la innovación y el cambio a través del cuestionamiento constante de transformar las formas habituales de la escolarización, promueven la investigación a nivel educativo, resistencia en los padres, directivos y docentes cuando se intenta llevar a cabo nuevos métodos de enseñanza, los valores predominan en las decisiones de los directivos y profesores.

\subsection{Procedimiento}

Una vez aplicado los instrumentos de investigación se procede a la organización, análisis e interpretación de la información, este proceso se aplica en el método de la triangulación para la tabulación de la información cuantitativa y cualitativa, a través de éste se analizarán los datos desde distintos ángulos para compararlos y constar con la utilización de los métodos correspondientes. 
Se procede a organizar la información empírica recabada con el trabajo de campo y organizada en tablas estadísticas. Cumplida ésta fase se procedió a procesamiento de la información, por su parte será un momento de integración lógica donde la realidad observada y reflejada en los datos obtenidos a través de los diferentes instrumentos de investigación aplicados, serán analizados e interpretados a la luz de las categorías conceptuales del marco teórico.

Esta parte del trabajo permitirá alcanzar los objetivos planteados, es este contexto, se llegará a formular las conclusiones del trabajo, las cuales reflejarán no el carácter acabado de la investigación, sino las nuevas inquietudes y problemáticas generadas a partir de este análisis.

\section{RESULTADOS}

\subsection{Los instrumentos de gestión educati- va en donde se evidencia la Gestión en el liderazgo y valores. El manual de la orga- nización.}

Esta institución educativa no cuenta con el manual de la organización. este manual de organización es un instrumento de trabajo necesario para normar una organización y precisar las funciones del personal que conforman en este caso de los centros educativos, delimitando a su vez responsabilidades y logrando mediante su adecuada implementación la correspondencia funcional entre puestos y estructura. Se utiliza para recabar información ya que ayuda a la recopilación de datos, su análisis correspondiente para identificar las actividades y la integración del manual, que sirven como una herramienta indispensable dentro de una institución educativa, como una guía que permite describir los procesos que se va a realizar.

\subsection{El código de ética}

Esta unidad educativa no cuenta con un código de ética, que es un documento formal que se caracteriza por detallar comportamientos que constituyen deberes éticos que son cumplidos por los miembros de la institución educativa para que se respeten los derechos de terceros, o bien actuaciones que han de ser evitadas, así como el modo de resolver determinados conflictos éticos que se pueden presentarse en la institución.

En éste código ético están incluidos temas directamente regulados por la ley y la realización de donaciones a personas o grupos, la prevención de conflictos de intereses, el respeto de la propiedad, el respeto a la privacidad de situaciones y contextos. Este instrumento es de gran ayuda para este centro educativo porque logran comportamientos éticos, aunque por su propia naturaleza se presenta limitaciones por ser excesivamente legalista, rígido, complejo. No existen las debidas motivaciones que perciben para una creación, siendo que son instrumentos para la mejora de la ética y que depende cómo son puestos en práctica y su alcance se limita a aquello que se regula.

\subsubsection{El clima escolar y convivencia con va- lores}

En esta Unidad Educativa Luis Rogerio Gonzáles, existen pocas comunicaciones entre todo el personal, tanto, directivo, administrado, docente y de servicio, hay falta de comunicación, no son informados oportunamente de ciertas situaciones que se dan en la institución, creando conflictos entre el personal, directivo y docente, por que el personal administrativo tienen mejores relaciones entre sí; pero propiamente el personal docente entre ellos existe un ambiente un poco hostil, con algunas discrepancias, cada uno de ellos creen que son excelentes maestros, sin aceptar y 
reconocer sus imperfecciones que sería lo recomendable para que asuman sus errores y cambien su comportamiento, y no sean notados por el estudiantado, padres de familia y la misma sociedad, ya que el docente es el ejemplo para sus alumnos.

\subsubsection{Dimensión pedagógica curricular y valores}

Esta institución educativa, como centro educativo está responsabilizado de acompañar a los educandos de tal manera que sean de verdad los sujetos y protagonistas de su proceso formativo, asumiendo una función más orientadora y preventiva. Buscan desde el análisis de las formas de enseñanza y los factores asociados a ésta, la aplicación de los enfoques curriculares y contenidos programáticos, develando las características de estilos y prácticas docentes predominantes, que favorecen el logro educativo de cada uno de los alumnos.

Los docentes de esta institución educativa no siempre se están capacitando, no tienen dominio acertado, en los que respecta de los enfoques curriculares, planes, programas y contenidos. Un gran porcentaje de docentes no tienen capacidad crítica, que no siempre planifican sus clases, lo improvisan y eso no es de un profesional de la educación, en la planificación está el cómo va a dar el contenido para que pueda desarrollar el proceso de la clase. Los docentes deberían proporcionar sus experiencias de aprendizaje en función de la capacidad. Ya que el profesorado por su formación. Si los docentes pusieran en práctica las experiencias de aprendizaje, ofrecerían a los estudiantes oportunidades diferenciadas en función de sus diversas capacidades, aptitudes, estilos y ritmos.

Los docentes deben demostrar confianza a los estudiantes en sus capacidades y eso ayu- daría a estimular constantemente sus avances, esfuerzos y logros.

En el establecimiento educativo debe favorecer el conocimiento y valoración de nuestra realidad multicultural; incentiva el cuidado de la salud, el aprecio por el arte y la preservación del ambiente.

La institución educativa no desarrolla al momento ningún tipo de investigación educativa. Que debería establecer un plan de investigación orientado a la mejora permanente de los procesos técnicos y didácticos de la institución.

Cuentan con un modelo de evaluación de los aprendizajes unificado para la institución, necesitan de aplicación, para desarrollar y aplicar en toda la institución y una metodología unificada de evaluación de aprendizaje.

Implanta y aplica los nuevos currículos basados en competencias laborales como organizadores de los procesos de enseñanza-aprendizaje. Todas las especialidades implantan los nuevos currículos.

La intuición educativa no cuenta con un plan de formación ocupacional para los ex alumnos desempleados y formación continua para trabajadores en activo y que pongan en conocimiento de instituciones públicas y privadas.

La comunidad escolar no se desenvuelve en un ambiente propicio para la práctica de valores universales tales como: la solidaridad, la tolerancia, la honestidad, y la responsabilidad, en el marco de la formación y la cultura de la legalidad. En este centro educativo la mayoría de los docentes no ponen en práctica los valores, ello pasa por desapercibido, permitiendo en muchos jóvenes el irrespeto hacia los mismos docentes y hacia la sociedad, formándoles unas personas con pocos valores y ética. Un 
establecimiento educativo no solamente tiene que formar en conocimientos, sino como personas aptas para poder desarrollarse y desenvolverse en la sociedad. A pesar que como asignatura tienen Desarrollo personal, simplemente la docente trata de cumplir con los temas, unas simples lecturas sobre determinados contenidos, pero no concientiza a que los alumnos pongan en práctica, comenzando dentro del aula y fuera de ello. Permitiendo que exista escasos en valores y virtudes que se deben adquirir y formar buenos hábitos como la prudencia, objetividad, la fortaleza, la magnanimidad que es el hábito en proponerse metas altas, la humildad que sería contar con la realidad del conocimiento propio y de todos quienes constituyen la institución.

\subsubsection{Dimensión organizativa operacional y valores}

La Institución educativa elabora un manual de procedimientos administrativos eficaz y transparente. Actualmente cuentan con el reglamento interno.

La institución educativa no cuenta con Planes de Transformación Institucional, están elaborando estos planes de Transformación Institucional para los ciclos de tres años comprometidos con las orientaciones del proceso de reforma y la misión institucional del sistema.

Cuentan con el Plan Operativo Anual (POA), vinculados con el cumplimiento de los objetivos estratégicos.

La institución educativa se autoevalúa, realiza el seguimiento y evaluación de sus acciones, busca la evaluación externa y las utiliza como una herramienta de mejora y no de sanción.

La institución educativa comparte una visión de futuro, planea sus estrategias, metas y actividades, pero no cumple con lo que ella misma se fija.

La rectora ejerce liderazgo académico, administrativo y social para la transformación de la comunidad escolar.

El personal directivo, docente y de apoyo trabaja como un equipo integrado, con intereses afines y metas comunes.

La institución educativa se autoevalúa, realiza el seguimiento y evaluación de sus acciones, busca la evaluación externa y las utiliza como una herramienta de mejora y no de sanción.

Promueve el desarrollo personal profesional de su personal dentro de su propio centro, mediante la reflexión colectiva y el intercambio de experiencias para convertirse en una verdadera comunidad de aprendizaje.

\subsubsection{Dimensión administrativa y financiera y valores}

Está a cargo de la Rectora, Consejo Directivo, Departamento Financiero

La institución educativa elabora un manual de procedimientos administrativos eficaz y transparente. Existe solamente reglamento interno.

La institución educativa está elaborando Planes de transformación institucional (PTI) para los ciclos de tres años comprometidos con las orientaciones del proceso de reforma y la misión institucional del sistema, pero aún no lo terminan, es decir no existen planes de transformación institucional.

Mejora las condiciones de su infraestructura material para llevar a cabo eficientemente sus labores: aulas en estado satisfactorio, mobiliario pintado y arreglado, equipo adecuado a 
los procesos modernos de enseñanza aprendizaje, laboratorios equipados, aunque no con la última tecnología, pero si aptos para poder desarrollar el proceso de enseñanza.

Los padres de familia están organizados y participan en las tareas educativas con los docentes, son informados con regularidad sobre el progreso y rendimiento de sus hijos y tienen canales abiertos para expresar sus inquietudes y sugerencias.

La institución educativa desarrolla actividades generadoras de recursos para garantizar, al menos la satisfacción de necesidades básicas de producción.

La institución educativa establece de forma consensuada, un sistema de evaluación del desempeño profesional de equipos docentes y directivo, estableciéndose criterios claros y conocidos por todo el personal del colegio.

La institución educativa elabora un catálogo de puesto de trabajo definiendo las funciones y tareas de cada perfil profesional competencias requeridas para el desempeño profesional. La delegación del roles y funciones se han hecho en base a las comisiones establecidas.

La institución educativa establece una tabla objetiva de compensaciones no salariales por servicios prestados para el personal de estructura del colegio. En la situación actual no se contemplan compensaciones no salariales en la institución educativa.

La institución educativa gestiona un convenio anual con una Universidad pública o privada para el establecimiento de un programa de becas y el desarrollo de un programa de orientación y animación para el seguimiento de estudios superiores de sus alumnos. En la actualidad cuentan con un convenio de culminación de estudios, mas no para becas
La institución educativa establece un programa de cooperación y orientación vocacional con al menos tres colegios de enseñanza primaria. Gestión de infraestructuras y recursos tecnológicos. Actualmente no se han establecido convenios con escuelas de la zona.

La institución educativa diseña un sistema de seguimiento de los resultados académicos obtenidos por los estudiantes. Con eta información se elabora y divulga un informe semestral de rendimiento académico de los alumnos, con la finalidad de establecer las medidas correctora oportunas. Se han realizado el seguimiento de los resultados académicos; no se han elaborado informes semestrales de rendimiento.

\subsubsection{Dimensión comunitaria y valores.}

La institución educativa establece de forma consensuada, un plan de participación de la comunidad educativa que especifique las responsabilidades, ámbitos de cooperación y participación en el control de gestión de los diferentes actores.

Establece un sistema de intermediación en el mercado de trabajo para apoyar la inserción laboral de los egresados y dar servicio a las pequeñas empresas generadoras de empleo que demanden personal cualificado, relaciones con empresarios de economías locales.

Establece un convenio con Cámaras y/u organizaciones profesionales para el desarrollo de un programa de pasantías.

Están iniciando para crear y mantener actualizado un inventario de profesionales que estén dispuestos a participar en actividades de orientación y asesoramiento laboral de los alumnos.

Están iniciando los trámites de vínculo con 
ONGS, realizando un proyecto anual potencialmente financiable por Instituciones Internacionales de cooperación y gestiona la búsqueda de recursos, con la colaboración del Programa Nacional de Bachillerato Técnico.

La participación de los padres de familia o representantes en el proceso educativo es de principal importancia para el colegio, además, se les invita a participar de ellas a través como por ejemplo de escuela para padres dirigidas por los profesores dirigentes de curso, donde se tratan temas relacionados con la problemática familiar y el desarrollo psico-social de los alumnos según su nivel de aprendizaje. El centro de padres informa periódicamente a los apoderados, aquellas actividades en las que pueden participar.

\section{DISCUSIÓN}

Luego de haber realizado la investigación y análisis de resultados del Instituto Tecnológico Superior "Luis Rogerio González". Se procede al análisis y explicación de los resultados. La forma de organización de los equipos de trabajo en el centro educativo el 100\% está a cargo de los coordinadores de área en quienes están centradas las tareas de coordinación y organización de equipos de trabajo en las diferentes áreas; al igual que los aspectos que se toman en cuenta para medir el tamaño de la organización se concentra el 100\%. Los resultados obtenidos en la institución, sin tomar en cuen-

Tabla 2.

FODA de la Unidad Educativa Luis Rogelio González.

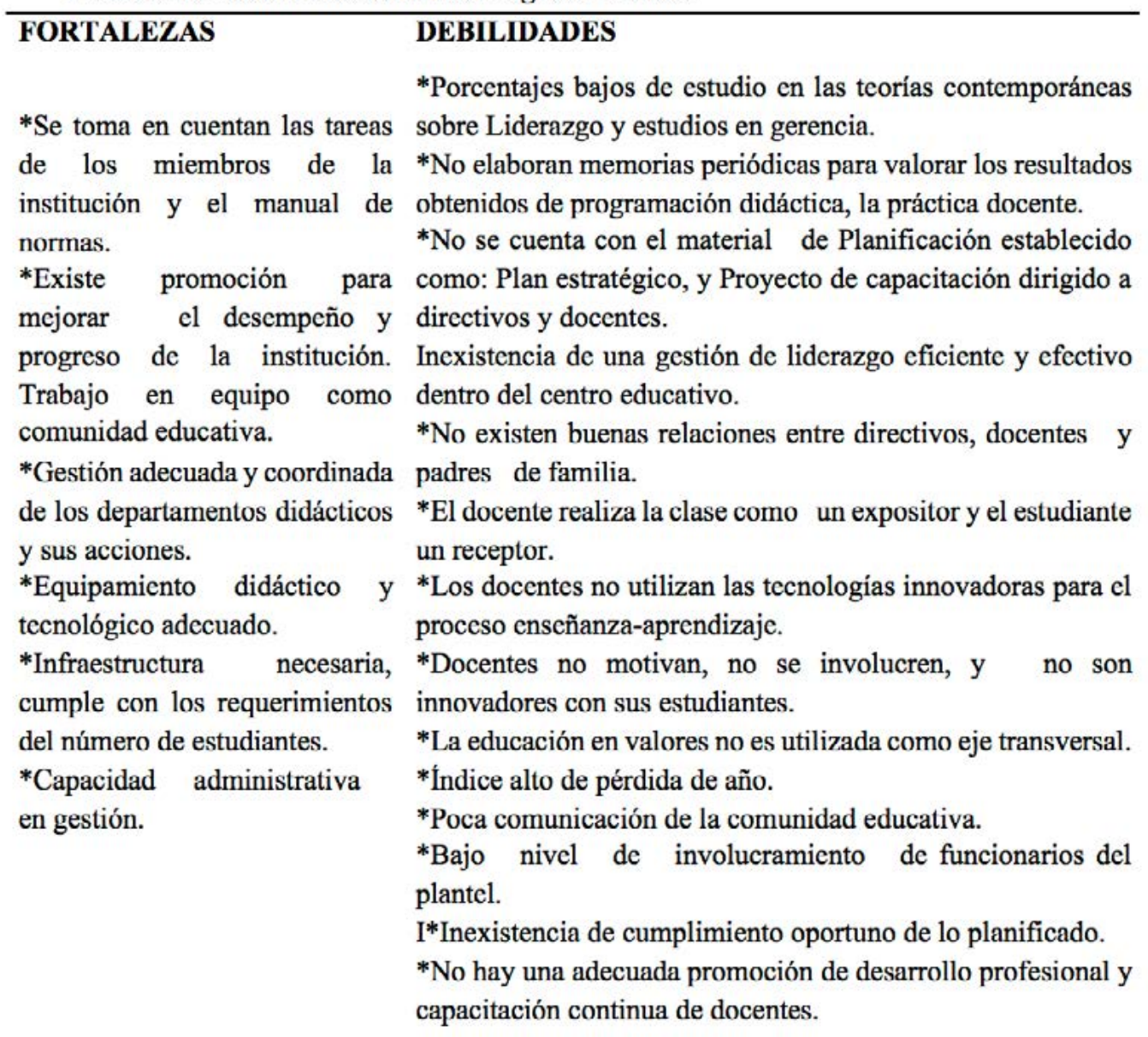

Pensamiento Americano Vol. 12 - No. 23 • 2019 • Enero - Junio • Corporación Universitaria Americana • Barranquilla, Colombia • ISSN: 2027-2448 · $\mathrm{http} / / /$ publicaciones.americana.edu.co/index.php/pensamientoamericano/index 


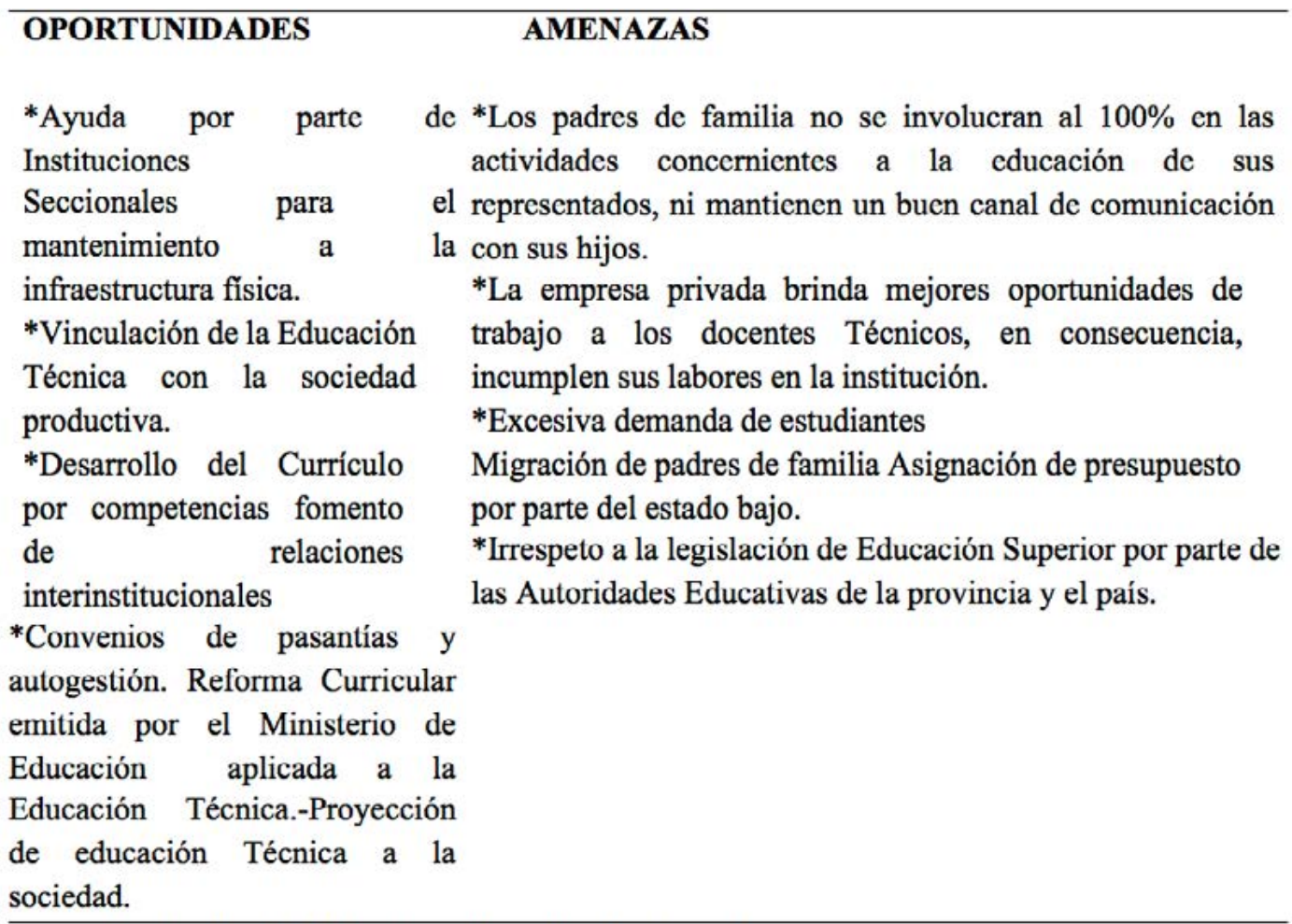

Fuente: Unidad Educativa "Luis Rogelio González"

Investigadora: Ana Castro Salazar, Fanny Cadme Galabay, Anita Naspud

Bonete

ta los otros aspectos el número de miembros ni el valor y tiempo empleado en la institución.

En un $100 \%$ se toman en cuentan las tareas de los miembros de la institución y el manual de normas, debido que este es un elemento indispensable para que puede funcionar o desarrollarse con éxito la institución. El clima de respeto y consenso en la toma de decisiones lo realiza el rector del establecimiento en un $75 \%$, es quien busca soluciones más apropiadas, contribuye con el desarrollo de comunidades profesionales, estimula el desarrollo organizativo, es capaz de identificar la cultura existente en el centro educativo y enfocarla hacia una visión institucional compartida, puesto que si no consigue dicha identificación encontrará resistencias al tratar de introducir cambios en beneficio de la institución que está al frente o su cargo (Quintana, 2006, p. 401). Reivindicación de un nuevo estilo para la investigación en organizaciones y dirección de centros educativos.

Para la toma de decisiones para resolver conflictos en un $75 \%$ se delega a un equipo, se considera un aspecto positivo el trabajar en equipo para la resolución de conflictos, estos se presentan en todo tipo de organización en este caso educativa, que son experiencias negativas, pero se trata de una percepción limitada porque todo conflicto tiene un aspecto muy positivo y es que conducen a que afloren problemas latentes que a partir de ese momento pueden ser analizados y resueltos, todos los conflictos cuya resolución se enfoque adecuadamente en una institución educativa constituye un poderoso agente de cambio positivo a nivel individual y a nivel organizativo, según sea la naturaleza de dicho conflicto, caso contrario un conflicto mal resuelto conduce inevitablemente a un deterioro, e incluso 
a la destrucción de la relación interpersonal existente entre los implicados y a difusiones organizativas. Para mediar el conflicto quien sea el delegado sería el directivo del centro educativo que es la figura que puede desempeñar un rol mediador en gran parte que lleve a analizar con las partes las posiciones enfrentadas, en lugar de decidir unilateralmente cual debe ser la solución, analizar las consecuencias previsibles de cada propuesta de solución, teniendo en cuenta las previsibles implicaciones que se puedan derivar para el colegio como por ejemplo las posible resistencias del profesorado, alumnado, padres de familia, etc. (Quintana, 2006).

Según las respuestas obtenidas de las encuestas a los directivos, se promueve en $100 \%$ el desarrollo profesional de los docentes, capacitación continua de docentes, trabajo en equipo; con la utilización de otras herramientas como la observación y encuestas a los docentes se ha podido determinar que dicha promoción no están efectiva como ellos expresan, puesto que, que no todos son docentes profesionales y no están capacitados que incluso un porcentaje considerable aún todavía no se capacitan en la nueva actualización y fortalecimiento curricular y dentro de cada una de las áreas de su especialización o de las asignaturas que están a su cargo; el 25\% de los padres de familia siempre participan en las actividades programadas y un $75 \%$ casi siempre, los padres de familia o representantes juegan un papel muy importante para la educación de sus representados y el establecimiento, es indispensable esta colaboración, que trabajen en conjunto toda la comunidad educativa que sería el éxito para la educación, lo que se esperaría que ese $75 \%$ sea el que "siempre" participe. Que se promueva en un 50\% la Excelencia Académica y vivencia de valores institucionales y personales es negativo que no exista un interés total en la promoción de estos dos aspectos que son fundamentales, porque sin
Excelencia Académica Total y Valores es difícil tener como resultado Calidad Total de Educación y sobre todo personas íntegramente formadas que eso se obtiene gracias a los valores.

Las habilidades de liderazgo un $75 \%$ son innatas, un $75 \%$ se logran estudiando las teorías contemporáneas sobre liderazgo y de igual manera con un $75 \%$ se desarrollan con estudios en gerencia, pero esto lo hacen "A veces", lo que indica que solo un $25 \%$ los hacen siempre. El rector es la figura más importante para el éxito de la interrelación centro educativo-comunidad, cuando no existe un coordinador escolar comunitario, el rector será un motivador, un líder, tanto instructivo, como en relaciones externas, un agente de acción. El rector tiene que crear y mantener actualmente una relación intensa con su entrono específico para conseguir la contribución externa a la vida del centro escolar, protegiendo al mismo tiempo al profesorado de las tensiones que puedan derivarse de este enfoque. Debe implicar a miembros interesados de la colectividad local en actividades escolares, los centros educativo actuales tienden a operar con políticas hacia su entorno más definidas que las tradicionales, por lo que el concepto de liderazgo escolar a nivel local está adquiriendo particular relevancia. La experiencia de la figura directiva y juicio profesional conducirá a la comunidad educativa a reconocer y aceptar su liderazgo educativo; además de una preparación académica en liderazgo y gerencia (Quintana, 2006, p. 256).

Se promueve el uso de la información de resultado de estudiantes, docentes y directivos con referencia para saber que les falta mejorar en un 100\%, dado como resultado comunicación efectiva en el centro educativo, puesto que las instituciones actuales realizan actividades escolares en la medida de sus posibilidades, muestran cada día un mayor interés por ofrecer toda su colaboración para la mejora de la labor específica que tiene que llevar a cabo 
dicha organización. Existe un ambiente muy cordial y agradable donde el alumno sea tratado de igual manera, así, respecto a las normas de comportamiento, la reacción del profesorado ante una determinada conducta del estudiante no está codificada hasta el punto de eliminar la interpretación de las actitudes del alumno en función de su conducta. En el centro educativo no debe haber temor de diferencias entre los directivos, profesorado y alumnado, encontrar el equilibrio justo y equitativo Si se mejora el desempeño y progreso del centro escolar y es lo que está haciendo este establecimiento educativo.

El 100\% de gestión que está bajo la responsabilidad delos directivos, lo realizan ejecutando acciones y haciendo el uso de los recursos ya sea técnico, financiero y humano. Mediante estos mecanismos permitirán gestionar y evaluar las políticas de responsabilidad social ética en la institución, tanto en el ámbito interno con externo, correspondería a cada institución decidir cómo gestionar las actividades que hacen referencia al desarrollo de sus miembrosy su cooperación al bien común del centro educativo. Con un porcentaje de $100 \%$ en otros a esto se refieren que, a más del personal administrativo, dirección técnica existen otras personas que integran la institución como otros organismos de coordinación docente, que se encuentran los departamentos de coordinación didáctica que se encargan en la organización y desarrollo de las enseñanzas propias de las materias o módulos que se les consideren orientación la colaboración y el trabajo en equipo del profesorado. Con un 75\% están de dirección, coordinación, con esto se puede apreciar que todos los organismos integran la institución, todos aportan con sus capacidades, aptitudes, etc. En beneficio de éste instituto tecnológico. Se llevan a cabo la evaluación o seguimiento global del grupo de alumnos, coordinan las actividades de enseñanza aprendizaje que se proponga a los alumnos lo hacen en un $100 \%$, en un $75 \%$ establecen las acciones necesarias para mejorar el clima de convivencia del grupo, un $75 \%$ tratan de forma coordinada los conflictos que puedan surgir en el grupo y establecer las medidas oportunas para resolverlos un grupo considerable si nos referimos al proceso aprendizaje es decir los nuevos conocimientos por parte de los estudiantes que se deben seguir diferentes perspectivas teóricas en general, enfatizando el rol de las experiencias y aprendizajes previos, ya que el éxito del aprendizaje depende en gran parte del punto de partida del sujeto la influencia del conocimiento previo en el procesamiento de la información. Si no se llevaría un seguimiento del alumnado cómo se podría saber cómo está su rendimiento escolar, para poder dar en informe de que la enseñanza se está impartiendo bien, o si se tiene que realizar algunas adecuaciones necesarias. De igual manera con un porcentaje del 100\% coordinan las actividades de enseñanza aprendizaje que se proponga a los alumnos y con un porcentaje del $75 \%$ establecen las acciones necesarias para mejorar el clima de convivencia del grupo es decir toman las acciones pertinentes para desarrollar relaciones afectuosas entre la comunidad educativa. Con un $75 \%$ tratar de forma coordinada los conflictos que puedan surgir en el grupo y establecer las medidas oportunas para resolverlos un grupo considerable. En este centro educativo en un gran porcentaje tratan de resolver los problemas existentes, lo analizan los problemas, tanto los pedagógicos, los derivados de la violencia escolar, de la droga, etc., para darles una orientación profesional y una solución a cada una de ellos, en algunos casos se tendrán que resolver con la ayuda de los padres de familia que suponen una ruptura de las barreras existentes, incluso se llegaría a la participación comunitaria que se llevaría a cabo a través de los consejos escolares.

Existe un 100\% de coordinación gestión 
adecuada y coordinada de los departamentos didácticos y sus acciones en, enseñanzas propias de cada materia, actualización de metodología, investigación educativa, prevención y detección de problemas de aprendizaje, lo que se hace al $75 \%$ es formular propuesta al equipo directivo y al claustro, referente a la elaboración de los proyectos, planes y programaciones de la institución, un 50\% no elaboran memorias periódica en la que se valore el desarrollo de programación didáctica, la práctica docente y los resultados obtenidos; en este centro educativo los departamentos didácticos están motivando un creciente interés por la innovación didáctica que están trabajando en conjunto para un notable incremento en respuesta a los nuevos planteamientos didácticos tomando como base la flexibilidad, con su aplicación pretenden dar cabida a la mayor variedad posible de situaciones de enseñanza-aprendizaje que pretenden convertirse en un centro educativo versátil. Actualmente las instituciones educativas tratan de mostrar un marcado interés por la mejora de calidad de vida escolar tanto con el alumnado y el profesorado (Quintana, 2006).

En un 75\% no cuentan con un plan estratégi$\mathrm{co}, \mathrm{y}$ proyectos de capacitación dirigidos a los directivos y docentes; y un 50\% no realizan Reingeniería de procesosy Plan operativo anual, estos aspectos son indispensables para el desarrollo del plantel sobre todo en la parte de gestión como tal, si no posee un plan estratégico que es el que define estrategias y políticas para lograr. El plan estratégico representa una serie de planes producidos después de un periodo de tiempo específico durante el cual se elaboran planes y es un proceso continuo en cuanto a la formulación de estrategias; de igual manera si no realizan proyectos dirigidos hacia los directivos y el profesorado, la preparación es necesaria en los centros de educación; están cometiendo un gran error ¿de qué educación de calidad hablamos? para la actualidad que los centros educativos tienen que responder a las necesidades de una comunidad más amplia, que estimula la flexibilidad organizativa y el cambio de prácticas rutinarias y excesivamente formalizadas, los centros educativos se encuentran actualmente inmersas en un proceso de cambios significativos en la organización y dirección, como consecuencia de un mayor interés en que estas instituciones proporcionen una respuesta adecuada a su entorno, preparando alumnos de calidad que estén en las mejores condiciones para continuar sus estudios o para un trabajo. También se observa en esta institución que con un 50\% en la reingeniería de procesos que es una metodología para la optimización institucional, este establecimiento educativo tiene la necesidad de rediseñar los sistemas o procesos que la integran, con el propósito de mejorar la calidad, eficacia, de modernizar la institución para que responda mejor a las necesidades de los alumnos (Quintana, 2006).

El 60\% los docentes a veces están de acuerdo que el rol del docente líder se define como una persona que posee la actitud y las habilidades para cuestionar las órdenes existentes. Quintana (2006), manifiesta "La gerencia educativa promueve el desarrollo de una comunidad profesional que es capaz de identificar la cultura organizativa existente en el centro educativo y enfocarla hacia una visión institucional compartida. Rol de la figura directiva, centros educativos innovadores, a veces con un $52 \%$ que no es muy considerable el directivo del centro educativo promueve a los padres, representantes comunidad en general la importancia en brindar a los estudiantes un ambiente de aprendizaje agradable, armónico, seguro y estimulante, esto quiere decir que el directivo no presta la suficiente atención al alumnado a que reciba una enseñanza en un ambiente agradable, creándose un clima de inseguridad. El directivo no puede limitarse solo a la gestión del centro educati- 
vo sino tiene que ser líder escolar estimulando el desarrollo de un buen clima institucional, buscando soluciones más apropiadas, impulsando a un verdadero desarrollo de la comunidad educativa; 64\% siempre los directivos y docentes promueven la investigación a nivel educativo porque es un producto de la participación colectiva donde se integran docentes, estudiantes, familias, asociación civil, padres y representantes, consejo comunal con el fin de desarrollar y materializar metas del centro educativo, siendo el estudiante investigador y crítico, el porcentaje del $76 \%$ a veces el trabajo en equipo para tomar decisiones de cambio de metodología de enseñanza-aprendizaje, en muy pocas ocasiones se reúnen los docentes del centro educativo para analizar cómo están trabajando que técnicas, métodos están utilizando dentro del aula para hacer que los estudiantes asimilen de la mejor manera, el $60 \%$ de los docentes dicen que no se sienten integrados en el colegio y entre sus compañeros, esto si es un gran problema de que no exista una buenas relaciones tanto con los directivos y compañeros del plantel, aquí, esta dificultad se da también por el cambio frecuente de los docentes contratados y el excesivo tamaño del centro y docentes, tienden a afectar de forma negativa al clima escolar y consiguientemente, el $60 \%$ a veces. El rector de este colegio tiene en cuenta las opiniones de los docentes y estudiantes, siendo que él es el que tiene que escuchar todas las sugerencias e inquietudes que serán para beneficio de todo el plantel educativo, no porque es la autoridad él siempre tiene la razón o es el que lo sabe todo y lo puede resolver, el 60\% a veces, las autoridades hablan más que escucha a los problemas de los estudiantes, y esto no se puede dar, el directivo de la institución mantendrá una buena relación con el alumnado, prestándole atención a sus problemas e inquietudes, hacer que expresen sus pensamientos y sentimientos y no solo el directivo sea el que tiene que hablar tendrá su razón,
En este caso sería que solo el docente es el que lo realiza la clase un expositor y el alumno un receptor; el 50\% de los docentes nunca inician la clase con frase motivación en valores y virtudes, considerando la realidad del entorno familiar y o comunitario. En la mayoría de veces el docente tiene que hacer relación los temas con los valores y virtudes, los docentes no solo estamos para dictar las cátedras, sino tenemos que educarles en valores, virtudes, el 60\% a veces los maestros proponen actividades innovadoras para que los estudiantes las desarrollen. Se dan estas debilidades por lo que los docentes no siempre están capacitándose cada vez, tal vez porque piensan que lo que ellos realizan dentro del aula es lo suficiente, o no disponen de tiempo, aunque nada de ello lo justifica, A veces con un 55\% Los métodos de enseñanza en las clases se caracterizan por la innovación, la variedad de participación y la interacción con los docentes. Aún en la actualidad existen docentes que a más de no innovarse, el docente es solo un mediador, un guía para que el alumno sea el que lo descubra, existe un 60\% que a veces los docentes se interesan por los problemas delos estudiantes, he tenido la oportunidad de hablar con varios de los docentes de esta institución educativa durante las encuestas a los maestros, y me han manifestado que cuando existen algún problema o inconveniente ellos o reportan al departamento del DOVE (Departamento de Orientación Vocacional de Estudiantes), y ellos no se involucran con el alumno que ellos están solo para enseñarles conocimientos, eso no debe ser.

Con un porcentaje considerables puede apreciar que los padres de familia a veces dedican tiempo a sus hijos, ocasionando que de ello existen hijos que hacen cosas inadecuadas para llamar la atención a sus padres, e incluso cuando están en la adolescencia consumen alcohol, droga y son muy rebeldes. De igual manera con un gran porcentaje que los padres 
de familia casi nunca preguntan a sus hijos por las actividades que realizan sus hijos en el centro educativo, deslindándose de su responsabilidad en guiar las tareas, los padres de familia castigan o toman represalias a sus hijos cuando no cumplen sus tareas escolares, ya sea físicamente o psicológicamente, un porcentaje muy considerable los padres de familia acuden al colegio para consultar notas, actos de indisciplina, o cuando lo invitan, o convocan, tal vez por no disponer del tiempo suficiente en poder acudir al colegio cuando lo necesiten o se interese pos sus hijos, no se mantienen buenas relaciones con el equipo directivo y profesores del centro educativo.

\section{CONCLUSIONES}

La forma de organización de los equipos de trabajo en el centro educativo el 100\% está a cargo de los coordinadores de área en quienes están centradas las tareas de coordinación y organización de equipos de trabajo en las diferentes áreas; al igual que los aspectos que se toman en cuenta para medir el tamaño de la organización se concentra el 100\%. Los resultados obtenidos en la institución, sin tomar en cuenta los otros aspectos el número de miembros ni el valor y tiempo empleado en la institución.

El clima de respeto y consenso en la toma de decisiones lo realiza el rector del establecimiento en un $75 \%$, es quien busca soluciones más a propiadas, quien contribuye con el desarrollo de comunidades profesionales, estimula el desarrollo organizativo, es capaz de identificar la cultura existente en el centro educativo y enfocarla hacia una visión institucional compartida, puesto que si no consigue dicha identificación encontrará resistencias al tratar de introducir cambios en beneficio de la institución que está al frente o su cargo (Quintana, 2006, p. 401).
Para la toma de decisiones para resolver conflictos en un $75 \%$ se delega a un equipo, se considera un aspecto positivo el trabajar en equipo para la resolución de conflictos, estos se presentan en todo tipo de organización en este caso educativa, que son experiencias negativas, pero se trata de una percepción limitada por que todo conflicto tiene un aspecto muy positivo y es que conducen a que afloren problemas latentes que a partir de ese momento pueden ser analizados y resueltos, todos los conflictos cuya resolución se enfoque adecuadamente en una institución educativa constituye un poderoso agente de cambio positivo a nivel individual y a nivel organizativo, según sea la naturaleza de dicho conflicto, caso contrario un conflicto mal resuelto conduce inevitablemente a un deterioro, e incluso a la destrucción de la relación interpersonal existente entre los implicados y a difusiones organizativas. Para mediar el conflicto quien sea el delegado sería el directivo del centro educativo que es la figura que puede desempeñar un rol mediador en gran parte que lleve a analizar con las partes las posiciones enfrentadas, en lugar de decidir unilateralmente cual debe ser la solución, analizar las consecuencias previsibles de cada propuesta de solución, teniendo en cuenta las previsibles implicaciones que se puedan derivar para el colegio como por ejemplo las posibles resistencias del profesorado, alumnado, padres de familia, etc. (Quintana, 2006).

El 100\% de gestión que está bajo la responsabilidad de los directivos, lo realizan ejecutando acciones y haciendo el uso de los recursos ya sea técnico, financiero y humano. Mediante estos mecanismos permitirán gestionar y evaluar las políticas de responsabilidad social ética en la institución, tanto en el ámbito interno con externo, correspondería a cada institución decidir cómo gestionar las actividades que hacen referencia al desarrollo de sus miembros y su cooperación al bien común del centro edu- 
cativo. Con un porcentaje de $100 \%$ en otros a esto se refieren que a más del personal administrativo, dirección técnico existen otras personas que integran la institución como otros organismos de coordinación docente, que se encuentran los departamento de coordinación didáctica que se encargan en la organización y desarrollo de las enseñanzas propias de las materias o módulos que se les consideren orientación la colaboración y el trabajo en equipo del profesorado. Con un 75\% están de dirección, coordinación, con esto se puede apreciar que todos los organismos integran la institución, todos aportan con sus capacidades, aptitudes, etc. en beneficio de este centro educativo.

Con un porcentaje considerable puede apreciar que los padres de familia a veces dedican tiempo a sus hijos, ocasionando que de ello existen hijos que hacen cosas inadecuadas para llamar la atención a sus padres, e incluso consumen alcohol, droga y son muy rebeldes. De igual manera con un gran porcentaje que los padres de familia casi nunca preguntan a sus hijos por las actividades que realizan sus hijos en el centro educativo, deslindándose de su responsabilidad en guiar las tareas, los padres de familia castigan o toman represalias a sus hijos cuando no cumplen sus tareas escolares, ya sea físicamente o psicológicamente, un porcentaje muy considerable los padres de familia acuden al colegio para consultar notas, actos de indisciplina, o cuando lo invitan, o convocan, tal vez por no disponer del tiempo suficiente en poder acudir al colegio cuando lo necesiten o se interese pos sus hijos, no se mantienen buenas relaciones con el equipo directivo y profesores del centro educativo.

\section{RECOMENDACIONES}

- Se promueva el desarrollo profesional de los docentes, capacitación continua de do- centes de manera efectiva y eficiente.

- Se formalice la educación en gestión y valores para la comunidad educativa de manera que se logre obtener líderes que tengan el perfil para estar al mando de los procesos vitales de la institución.

- Se fortalezca las relaciones entre: Directivos, Docentes, Padres de Familia, de manera que haya integración e involucramiento en todas las actividades con cada uno de los miembros.

- Que los docentes motiven, se involucren y sean innovadores con sus discentes.

- Que se fortalezcan los valores tanto en el involucramiento de estos en cada una de las clases impartidas, así como en todas las actividades que se lleven a cabo en la institución educativa. 


\section{Referencias}

Davis, D. (2003). Comportamiento humano en el trabajo. Octava Edición. México: McGraw-Hill.

Del Río Vásquez, J. (2005). Gestión organizacional en entornos complejos por parte de las Mipymes del sector servicios de la ciudad de Sincelejo. Revista Tendencias XVIII (2). 45-57.

Keith, D. (2003). Comportamiento humano en el trabajo: México.

Martínez, R. (2000). Evaluación de la Gestión Universitaria. CONEAU. Recuperado de: https://eco.mdp.edu. ar/cendocu/repositorio/00091.pdf

Quintana, A. (2006). Las tareas administrativas.

Santos, J. (8 de febrero de 2008). Liderazgo Sintergial y Retcambio. PsicoPediaHoy, 10(6). Recuperado de: http://psicopediahoy.com/liderazgo-sintergial-retcambio/

2018, Vol. 12(23) 105-126 @The Author(s) 2018 Reprints and permission: www.americana.edu.co 